\title{
Strength analysis of aluminium foil parts made by composite metal foil manufacturing
}

\author{
Javaid Butt $^{1} \cdot$ Habtom Mebrahtu ${ }^{1} \cdot$ Hassan Shirvani ${ }^{1}$
}

Received: 24 December 2015/Accepted: 21 March 2016/Published online: 5 April 2016

(C) Springer International Publishing Switzerland 2016

\begin{abstract}
A number of different parts for mechanical testing were produced using composite metal foil manufacturing (CMFM). This process is a combination of laminated object manufacturing and brazing technology. Aluminium is one of the toughest metals to join and CMFM can achieve this task with ease. By using aluminium 1050 foils of $0.1 \mathrm{~mm}$ thickness, various parts were made according to British and International Standards, including lap joints, peel specimens, dog-bone specimens and tested for their mechanical properties. A special, $80 \%$ zinc and $20 \%$ aluminium by weight, brazing paste was utilized for joining the foils together. The test of the single lap joints show that none of the specimens failed at the bonded area and the failure was always due to fracture of the parent metal. Cohesive failure was also observed for the single lap joints by using $10 \mathrm{~mm}$ thick aluminium metal plates. It helped in calculating the lap shear strength which is a useful design parameter. The peel test showed good bond consistency in all the specimens with an average peel strength of $20 \mathrm{MPa}$. Comparative tensile test was conducted with a dog-bone specimen machined from a solid block of aluminium 1050 and specimens made with CMFM. The results showed that the specimens made by CMFM fracture at force values that are higher than that of the parent metal. This demonstrates that CMFM has the
\end{abstract}

Javaid Butt

javaid.butt@anglia.ac.uk

Habtom Mebrahtu

habtom.mebrahtu@anglia.ac.uk

Hassan Shirvani

hassan.shirvani@anglia.ac.uk

1 Engineering \& Built Environment, Anglia Ruskin University, Bishop Hall Lane, Chelmsford CM1 1SQ, UK capability to produce high quality and stronger parts as compared to conventional machining methods employed for the production of metal parts. The effect of using different number of layers for the same cross-sectional area has also been investigated.

Keywords Additive manufacturing - Brazing · Laminated object manufacturing - Lap-shear testing . Metal foil - Metal parts - Peel test - Tensile testing

\section{Introduction}

Additive manufacturing (AM) of metal parts provides solutions to real-world problems as they can be tested under similar conditions to show their behaviour. A large number of AM processes are commercially available that use plastics, polymers, photopolymers, ceramics, etc. to produce parts [1-5]. These parts mainly serve as prototypes and do not give any insight into the design parameters. There has always been an emphasis on the production of metal parts using AM because it provides an environment for direct testing. Furthermore, AM methods can produce complex geometries like conformal cooling channels for injection moulding, which are not possible with conventional machining/subtractive techniques. A couple of commercially available AM processes capable of producing metal parts are direct metal laser sintering (DMLS) and electron beam melting (EBM). They use powder metals and have been widely researched over the years [6-10]. Although these technologies are capable of producing good quality parts, they still do not ease the pressure when it comes to the production of metal parts because of the very high cost of their machines and inability to cope with the material requirements $[11,12]$. They have a number of 
limitations like materials, particular grain size of powder metal to achieve certain degree of mechanical integrity, size of parts being made, build speed, surface finish, etc. Also, after production, the powder removal process requires more time and thus reduces the efficiency of the process $[13,14]$. Therefore, efforts were made to overcome these limitations and other AM technologies were pursued. This idea led to the modification of laminated object manufacturing (LOM). The LOM method originally made use of paper sheets with adhesives on one side but since the setup was cheap, further materials including plastic and metal laminates were experimented with, to enhance the capabilities of this technology [15]. One such method is known as metal foil LOM (laminated object manufacturing) and uses metal sheets for the production of parts. It was an experimental approach that was aimed at the production of large moulds. For the structural stability of the parts, Metal Foil LOM can only work with foils having a thickness of more than $0.5 \mathrm{~mm}$ as anything less than that results in a significant staircase effect. The produced parts are not of very good quality either and have a poor surface finish. Post processing is required to improve the mechanical properties of the parts which makes the process inefficient $[16,17]$. Epoxy adhesives and glues have also been used to join metals sheets together using LOM but the produced parts are far from perfect in terms of their material properties and in some cases serious failures have occurred $[18,19]$. Another method that has shown promise is known as ultrasonic consolidation (UC). It has shown great promise in working with difficult metals like aluminium and stainless steel. It combines ultrasonic seam welding of metals and layered manufacturing techniques to build up a solid freeform object. The process uses a sonotrode connected to a transducer to apply pressure and ultrasonic oscillations for bonding. The process is repeated until the required height is achieved and then a CNC (computer numerical control) mill is used to trim the excess foil from the component and achieve the required geometry. Another finishing mill is brought into action to create the required tolerance and surface finish. After the trimming and finishing, the finished part is removed from the anvil [20,21]. The biggest challenge of this process is optimization of the process for bond density and plastic flow to have a better contact between the foils [22]. All of these processes have been researched upon and parts have been produced using them but they are limited in what they can do and achieve in terms of producing metal parts.

In addition to making metal parts by alternative and cheaper methods, the production of composite materials has been receiving unprecedented attention from the academia, mainstream media, investment community and national governments around the world. Metal composites or metal matrix composites (MMCs) are gaining popularity because a number of industries rely on them to provide cheaper, lighter, and stronger alternatives. AM processes are not far behind in this endeavour either and a number of them have produced MMCs including selective laser melting/sintering (SLM/SLS), laser engineered net shaping (LENS), three-dimensional printing (3DP), LOM and UC. However, it required a great degree of additional equipment and time to produce a metal composite using AM processes and their mechanical integrity in some cases is far from ideal [23-25].

This study clearly indicates that there is a gap that needs to be filled when it comes to the production of cheap and high-quality metal parts. The limitations related to conventional metal AM methods have to be minimised to make way for better and efficient product development. Another process has joined the list of metal AM methods capable of using metal foils for the production of functional parts and is termed as composite metal foil manufacturing (CMFM). It combines the simplicity of LOM with the flexibility of brazing. This integration makes the process adaptable to changes. A model of a machine based on the principle of CMFM is shown in Fig. 1. The product development has two stages-the principles of LOM for cutting and placing of sheets and brazing to join the foils and produce a part. Brazing is similar to soldering, but the main difference lies in the operating temperatures as joining operations that are under $450{ }^{\circ} \mathrm{C}$ are considered to be soldering and those above $450{ }^{\circ} \mathrm{C}$ lie under brazing. Copper, silver, and gold are easy to braze because they have good braze-ability. Iron, mild steel and nickel are next in difficulty. Because of their thin, strong oxide films, stainless steel and aluminium are even more difficult to braze. A detailed description of the process has been presented in our previous research along with the testing of copper foils to establish the effectiveness of the process

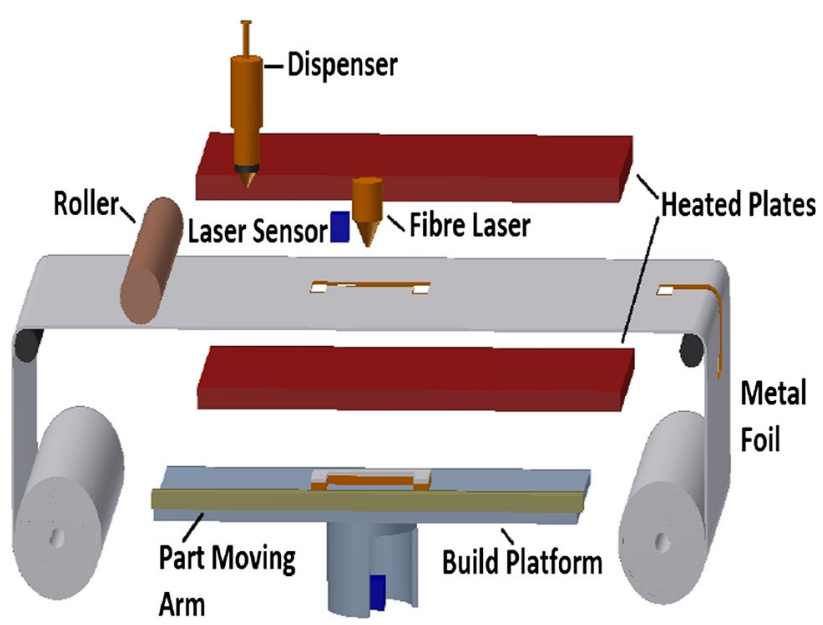

Fig. 1 Composite metal foil manufacturing process 
$[26,27]$. To demonstrate the flexibility of the proposed process, $0.1 \mathrm{~mm}$ thick Aluminium 1050 grade foils with H14 1/2 hard temper were chosen for the research work. Aluminium is one of the hardest metals to braze and various aluminium alloys have different braze-ability: 1xxx, $2 \mathrm{xxx}, 3 \mathrm{xxx}, 4 \mathrm{xxx}$, and $7 \mathrm{xxx}$ are easier to braze than the $6 x x x$ series alloys. Magnesium content in the $5 x x x$ series alloys makes them the most difficult to braze. It is because in addition to the oxide layer of aluminium, the oxide layer of magnesium needs to be removed as well to perform the brazing process. The magnesium oxide layer also forms on contact with air so instead of one, now there are two layers to remove for joining aluminium alloys containing magnesium [28]. The removal of the oxide layer is the key to the brazing process as once it is removed; the process can go on easily. Aluminium oxide is not so easily removed and requires stronger fluxes that can go up to temperatures of $550{ }^{\circ} \mathrm{C}$. In case of very thin aluminium foil, which is the case for this research work $(0.1 \mathrm{~mm})$, there is a danger of pitting so proper care must be given in dealing with such cases. For these reasons, $80 \%$ zinc and $20 \%$ aluminium by weight brazing paste with non-corrosive flux was chosen to produce aluminium specimens. The melting point of the brazing paste in use ranges between 410 and $470{ }^{\circ} \mathrm{C}$ and it becomes liquid in this range. However, it should not be kept at these temperatures for longer periods of time as the flux would burn off and the paste would not be able to penetrate the tenacious oxide layer on the surface of the aluminium foil.

\section{Experimental procedure}

CMFM is an extremely complex process and a number of different components have to work together in complete harmony to produce parts. That is why the complex process was broken down into simple independent steps for practicality. An experimental procedure was devised to create metal parts using metal foils. The use of metal foils makes the production of parts very cheap as compared to other AM methods. The process of brazing can be tricky for aluminium; therefore, it was essential that proper care was given to every specimen. The ability of the process to work with difficult metals such as aluminium is what makes it flexible as well as adaptable; two characteristics that are very important in a metal parts manufacturing system.

The foils of aluminium were used as supplied without any surface treatment as it takes time and one of the key features of the process is that it reduces the production time to a great extent compared to other AM methods. The foils were cut and then deposited with brazing paste. Every specimen was sandwiched between two stainless steel plates fitted with nuts and bolts. At any given time, only one specimen was placed inside the plates and a uniform layer of paste was achieved by tightening the nuts with a torque wrench. The use of torque wrench ensured that repeatability can be observed in all the specimens by creating a uniform layer of paste equal to $0.1 \mathrm{~mm}$. The plates along with the paste-coated foils were placed inside a furnace. The structure was heated for a pre-defined time based on the thickness of the specimen being produced and then taken out. No post-processing is required to enhance the mechanical characteristics; therefore, after cooling the specimen could be used for testing. This setup was instrumental in determining some key aspects of the process and helped in eliminating the guesswork when test specimens were made using components of the real machine.

Three tests, including lap-shear test, peel test and comparative tensile test, were carried out to assess the capability of CMFM while working with difficult metals. Specimens were produced using $0.1 \mathrm{~mm}$ thick Aluminium 1050 grade foils with a $\mathrm{H} 14 \frac{1}{2}$ hard temper bonded by a special, $80 \%$ zinc and $20 \%$ aluminium by weight, brazing paste. Tables 1 and 2 show the composition and mechanical properties of the materials used. British and International Standards were followed for the production of parts and testing. The tests presented in this research analyse the tensile properties of the specimens and assess the capability of the process in making parts that provide consistent results and better material properties compared to conventional subtractive technologies.

\subsection{Tensile lap-shear test}

Single lap joints using foils of $0.1 \mathrm{~mm}(\mathrm{t})$ thickness are not generally produced which accounts for the lack of specific standards for such thickness. However, BS EN 1465: 2009 [29] was followed and INSTRON 5582 machine was operated at a speed of $10 \mathrm{~mm} / \mathrm{min}$ for testing. The

Table 1 Chemical composition of materials

\begin{tabular}{lllllllll}
\hline Materials & \multicolumn{7}{l}{ Chemical composition (in weight \%) } \\
\cline { 2 - 9 } & $\mathrm{Cu}$ & $\mathrm{Si}$ & $\mathrm{Fe}$ & $\mathrm{Mn}$ & $\mathrm{Mg}$ & $\mathrm{V}$ & $\mathrm{O}$ & $\mathrm{Al}$ \\
\hline $\mathrm{Al} 1050$ & 0.05 & 0.25 & 0.40 & 0.05 & 0.05 & 0.05 & - & Balance \\
\hline
\end{tabular}

Table 2 Mechanical properties of materials

\begin{tabular}{lll}
\hline Mechanical properties & Materials \\
\cline { 2 - 3 } & Al 1050 H14 & Brazing paste \\
\hline Yield strength (MPa) & $105-145$ & 45 \\
Tensile strength (MPa) & 120 & 60 \\
Young's modulus (GPa) & 69 & 60 \\
\hline
\end{tabular}




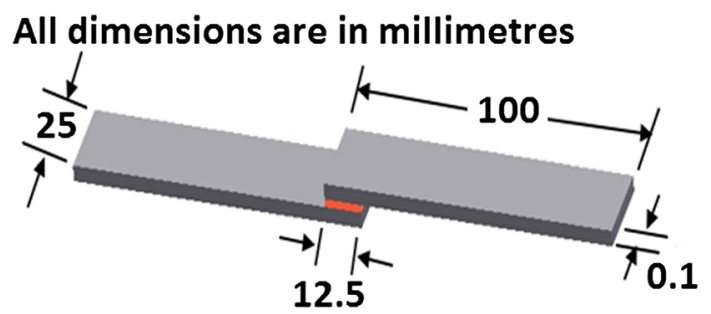

Fig. 2 Dimensions of lap joint [29]

dimensions of the specimen are shown in Fig. 2. The thickness of the brazing paste was kept at $0.1 \mathrm{~mm}$; therefore, the final thickness of the brazed region will be $0.3 \mathrm{~mm}$.

\subsection{Peel test}

BS EN ISO 11339:2010 [30] was followed for the production and testing of the peel specimen. The testing machine was operated at a speed of $10 \mathrm{~mm} / \mathrm{min}$. The dimensions of the specimen are shown in Fig. 3. The thickness of the paste was kept at $0.1 \mathrm{~mm}$ which makes the overall thickness of the $150 \mathrm{~mm}$ bonded region as $0.3 \mathrm{~mm}$.

\subsection{Tensile testing for dog-bone specimens}

The dog-bone specimens for tensile test were produced in accordance with ISO 6892-1 [31]. A specimen was machined out of a solid aluminium 1050 block and then compared to parts produced by CMFM. Three specimens were produced using foils of $0.05,0.1$ and $0.2 \mathrm{~mm}$ thickness. The reason for making three different specimens with foils of different thickness is to analyse their effect. The dimensions of the specimen are shown in Fig. 4, whereas Table 3 shows the specification of the three specimens.

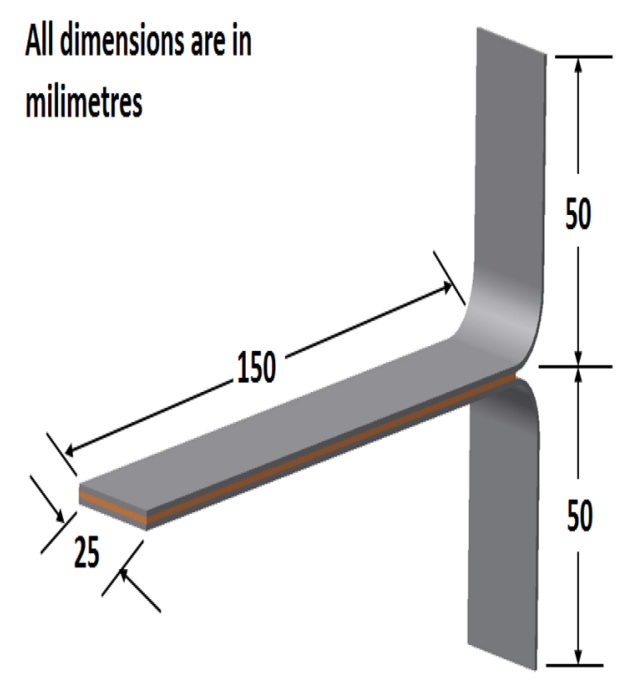

Fig. 3 Dimensions of T-peel specimen [30]

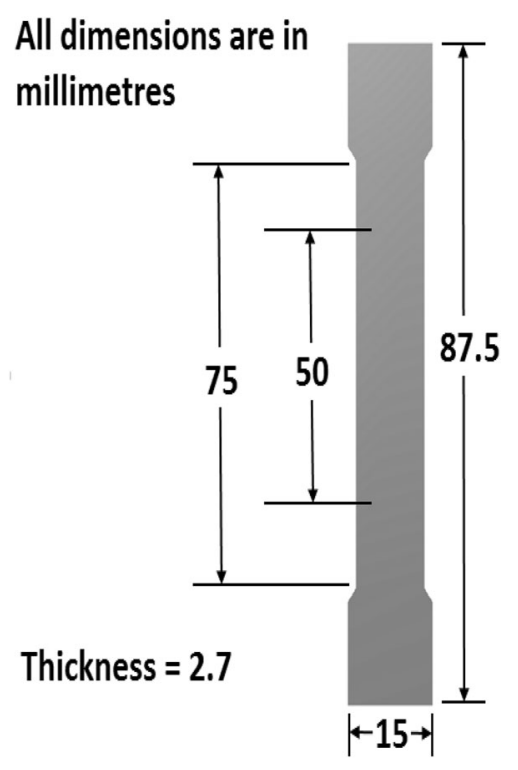

Fig. 4 Dimensions of the dog-bone specimen [31]

Table 3 Specification of the aluminium specimens

\begin{tabular}{ll}
\hline Thickness $(\mathrm{mm})$ & Number of foils \\
\hline 0.05 & 18 \\
0.1 & 14 \\
0.2 & 9 \\
\hline
\end{tabular}

For all the specimens the overall thickness was the same but the individual thickness of the foils differ. The thickness of the paste was again kept at $0.1 \mathrm{~mm}$.

\section{Results and discussion}

\subsection{Results from lap-shear test}

The single lap joints produced by CMFM fractured within the base metal, whereas the brazed zone was unaffected. This shows that the bond is stronger than the material. Such a fracture occurred because less force is needed for failure of the single foil compared to the bonded region that has twice the thickness. Lap-shear testing is generally affected by lap joint length, gauge length and asymmetric loading. These factors were kept in check to ensure consistent testing conditions. Figure 5 shows the failure modes of the lap-shear specimens and the test results are shown in Fig. 6. The failure mode was substrate failure (SF) according to BS EN ISO 10365:1995 [32].

Two different modes of failure were observed from the testing:

1. When the fracture was at the base metal adjacent to the brazed region as seen for S1, S2 and S3. Such a failure 

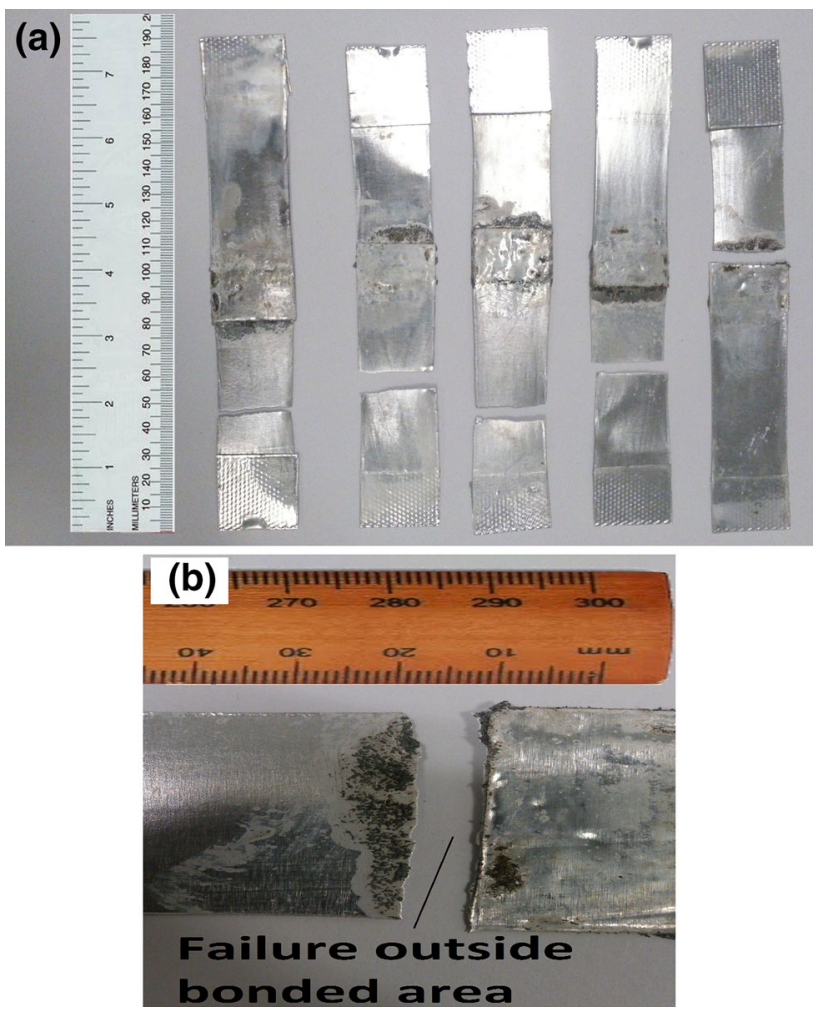

Fig. 5 Failure modes of lap-shear specimens

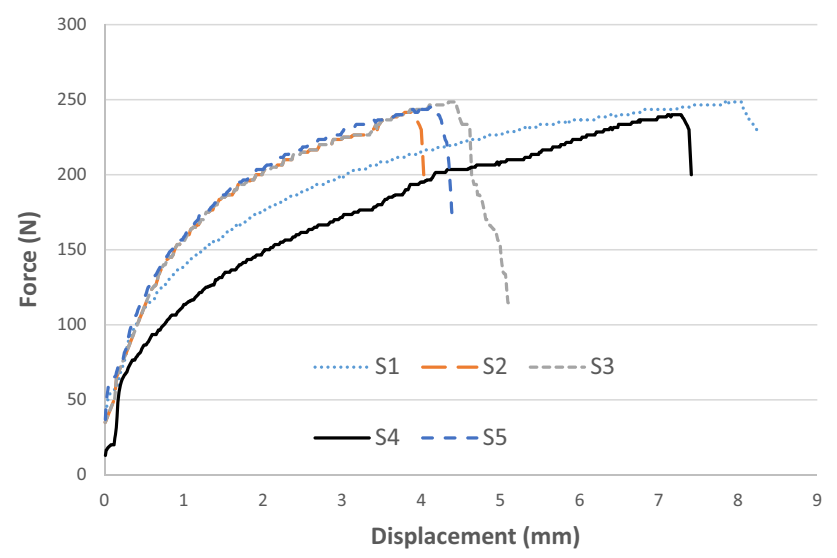

Fig. 6 Lap-shear test results

is characterized by a smaller displacement range to failure. Smaller displacement range resulted in smaller plastic deformation of the foil before failure. Once a crack was initiated, it ran across the width of the foil to cause fracture.

2. When a break occurs away from the bonded area. Stretching of the foil on either ends of the bonded area led to a fairly larger displacement range in the case of S4 and S5.

\subsubsection{Calculation of lap-shear strength}

For industrial applications, tensile lap-shear strength of the bond or in other words joint tensile strength $(\sigma)$ is important; therefore, lap joints with $10 \mathrm{~mm}$ thick Al 1050 plates were made according to BS EN 1465: 2009. The reason for the mentioned thickness is that anything less than that resulted in substrate failure, and calculation of joint tensile strength requires cohesion failure which can be observed with $10 \mathrm{~mm}$ thick plates.

The bond strength $(\tau a)$ has been calculated as a maximum shear stress achieved in the bond layer, based on recorded maximum tensile forces for each tested joint: $\tau \mathrm{a}=F_{\max } /$ Length of the lap joint $\times$ width of the substrate.

The joint tensile strength $(\sigma)$ as a maximum tensile stress transferred crossover the joint:

$\sigma=F_{\max } /$ Thickness of the substrate $\times$ width of the substrate.

The values of the bond shear strength and joint tensile strength are calculated using Eqs. (1) and (2). They are presented in Table 4.

The experimental calculation yields shear strength of $52.378 \mathrm{MPa}\left(\mathrm{N} / \mathrm{mm}^{2}\right)$ for the bond produced by the brazing paste used. This value is quite high as compared to some of the industrial adhesives [33] including a very ductile polyurethane adhesive (Sikaflex-255 FC with a shear strength of $8.26 \mathrm{MPa}$ ), a very brittle two-component epoxy adhesive (Araldite ${ }^{\circledR}$ AV138/HV998, with a shear strength of $30.2 \mathrm{MPa}$, from Huntsman), and an intermediate twocomponent epoxy adhesive (Araldite ${ }^{\circledR}$ 2015, with a shear strength of $15.9 \mathrm{MPa}$, from Huntsman). The joint tensile strength is $62.864 \mathrm{~N} / \mathrm{mm}^{2}$ and must be kept in mind while designing products using CMFM.

\subsection{Results from peel test}

The bond effectiveness was determined by the peel test. The specimens had a bond thickness of $0.1 \mathrm{~mm}$; therefore, the thickness of each specimen becomes $0.3 \mathrm{~mm}$ after it has been produced and is ready for testing. The results of a peel test are generally influenced by peel angle and peel rate: therefore, special care was given to keep them constant for the five specimens. The peel rate was $10 \mathrm{~mm} / \mathrm{min}$ and the peel angle was $180^{\circ}$. Figure 7 is the graphical representation and Fig. 8 shows the two failure modes observed during the peel test.

The peel test resulted in two failure modes (Fig. 9):

1. When a specimen shows less and small teeth at the beginning of the brazed region indicating a strong bond 
Table 4 Calculation of joint tensile strength at $12 \mathrm{~mm}$ overlap length
Fig. 7 Fracture modes of aluminium peel test

\begin{tabular}{llll}
\hline Specimens & $F_{\max }(\mathrm{N})$ & Bond shear strength $(\mathrm{MPa})$ & Joint tensile strength $(\mathrm{MPa})$ \\
\hline S26 & 15,520 & 51.73 & 62.08 \\
S27 & 15,600 & 52 & 62.4 \\
S28 & 16,000 & 53.3 & 64 \\
S29 & 15,560 & 51.86 & 62.24 \\
S30 & 15,900 & 53 & 63.6 \\
& & Average $=52.378$ & Average $=62.864$ \\
\hline
\end{tabular}

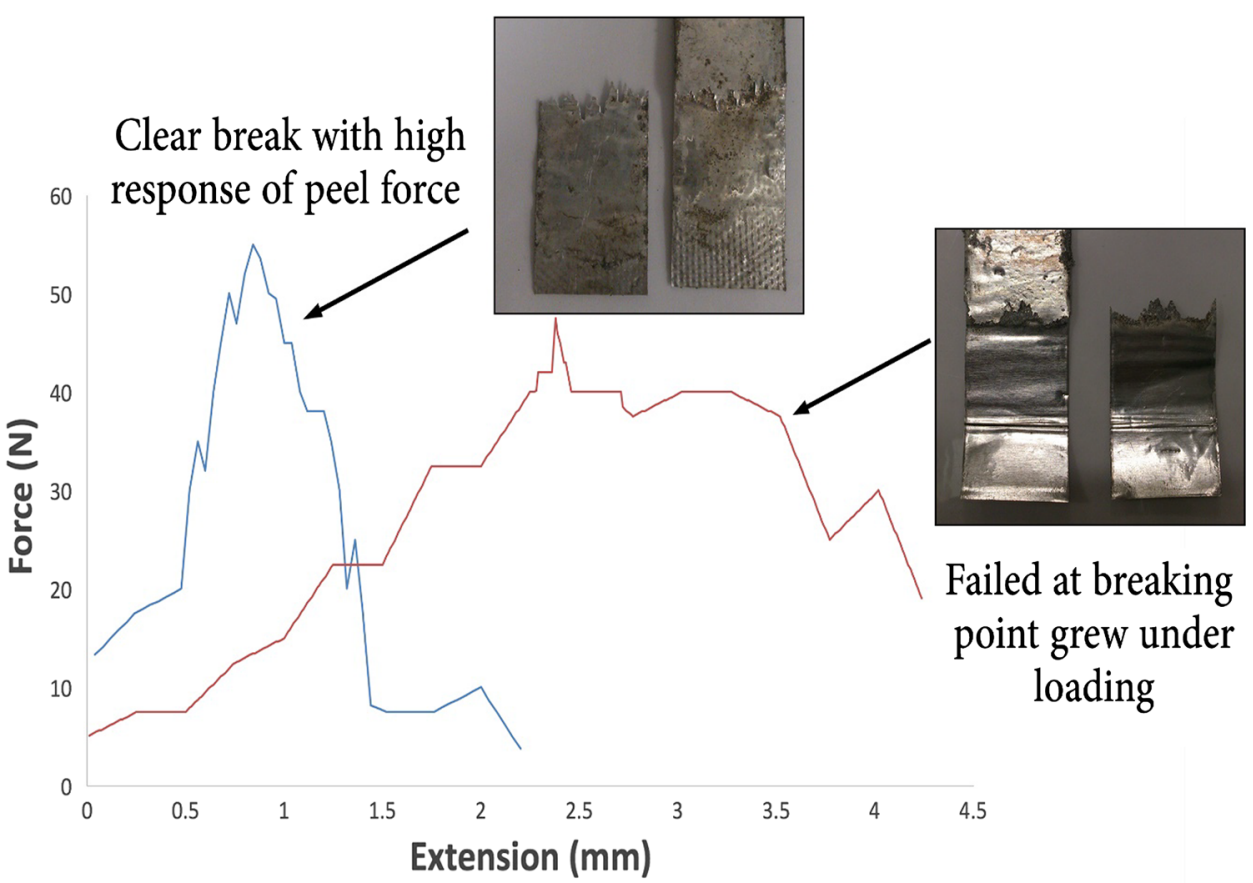

between the two foils, giving a high load ranging from 55 to $50.5 \mathrm{~N}$.

2. When a specimen shows a large number of teeth resulting in more breaking points that grew as the load is being applied. Such failures result in comparatively low force values of around 45.5 N.

Table 5 calculates the average force (from the graph) and peel strength which is obtained by dividing the maximum force with the cross-sectional area $(0.1 \times 25 \mathrm{~mm}=$ $2.5 \mathrm{~mm}^{2}$ ) of each specimen.

The maximum force for the peel tests was much lower than the maximum force for Al 99.5 which is $250 \mathrm{~N}$ (100 MPa or $100 \mathrm{~N} / \mathrm{mm}^{2}$ ) for a cross-sectional area of $2.5 \mathrm{~mm}^{2}(25 \times 0.1 \mathrm{~mm})$. These test results differ significantly from adhesive bonds that fail uniformly upon the application of load. When a load was applied to the brazed specimens, they showed the formation of teeth. The reason for the formation of teeth is the presence of un-bonded area indicating an absence of bond between the two foils. The teeth signify the integrity of the bond produced by CMFM.
Smaller teeth indicate a better bond, whereas larger teeth signify a poor bond. The presence of un-bonded areas can be attributed to the application of insufficient force during brazing, resulting in the paste not being able to penetrate the tenacious oxide layer at the interface. The peel test proved useful in understanding the overall bond effectiveness produced by CMFM. The substrate failed by splitting in layers; therefore, the failure pattern was given the designation DF (delamination failure).

\subsection{Results from dog-bone tensile test}

The tensile test was carried out to analyse the behaviour of the specimens produced by CMFM under tensile forces. This test clearly demonstrates that bond produced by CMFM fractures at a higher force value compared to a part product manufactured from conventional machining methods. Figure 10 shows the fracture modes of aluminium and one of the composite specimens. Figure 11 shows the comparison among the specimens. 
Fig. 8 Two fracture modes: a less and regular teeth; $\mathbf{b}$ more and irregular teeth
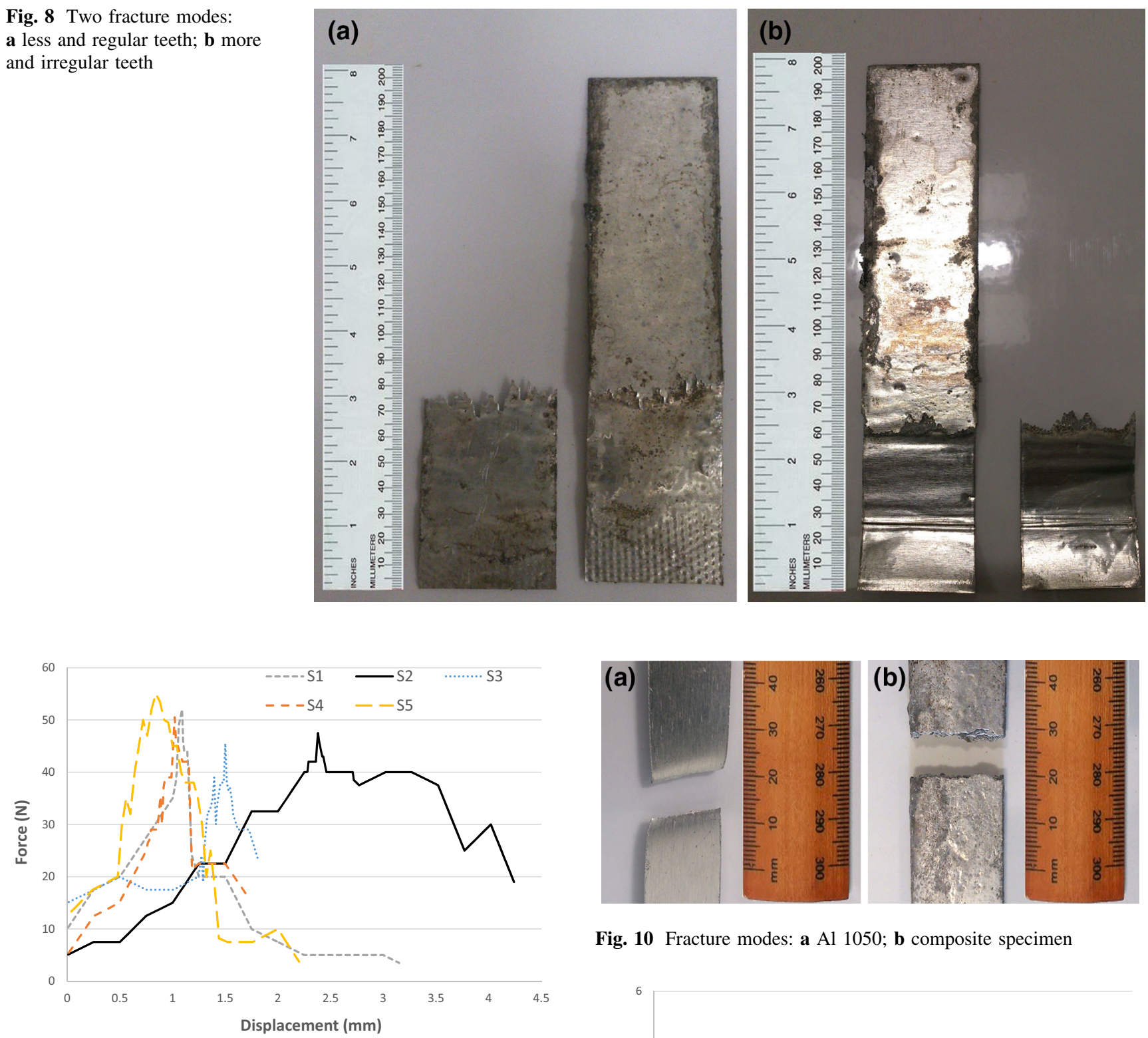

Fig. 10 Fracture modes: a Al 1050; b composite specimen

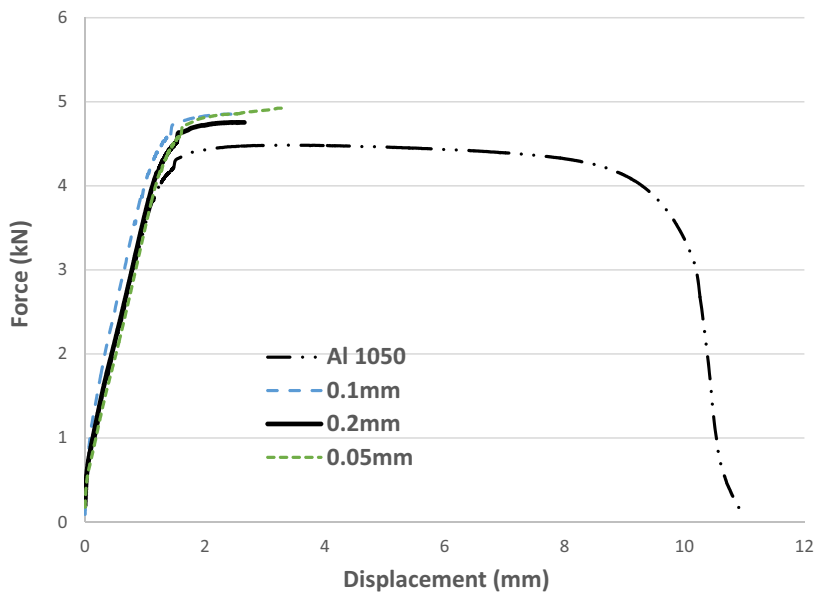

Fig. 11 Comparative tensile test

aluminium alloy. On the other hand, the specimen made up of 18 layers $(0.05 \mathrm{~mm}$ thick foils) showed maximum force value of $4.923 \mathrm{kN}$, the specimen made up of 14 fined elastic and plastic regions as is expected from an 


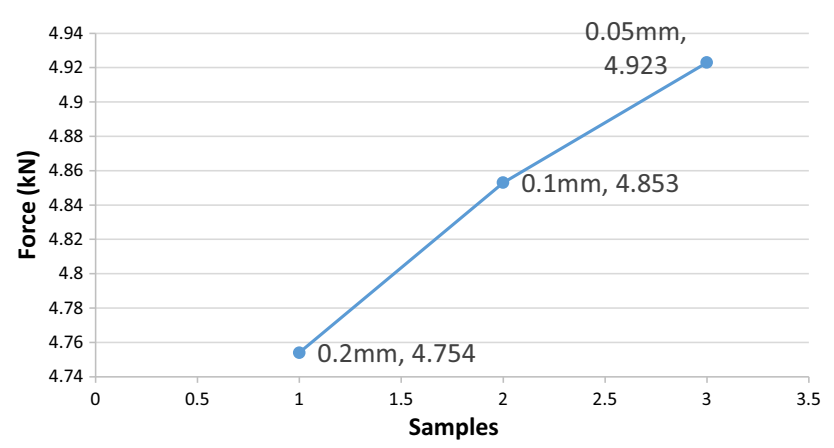

Fig. 12 Relationship between strength and foils of different thickness

layers $(0.1 \mathrm{~mm}$ thick foils) showed value of $4.853 \mathrm{kN}$ and the specimen made up of nine layers $(0.2 \mathrm{~mm}$ thick foils) showed value of $4.754 \mathrm{kN}$. The first specimen showed $9.8 \%$, second showed $8.25 \%$ and the third showed $6 \%$ higher force values as compared to the parent aluminium. The values obtained from the tensile test are plotted in Fig. 12 which shows a linear relationship between number of layers and force values. It clearly indicates that the more the number of layers used for a particular thickness, the more the force required to fracture the part.

The specimens produced by CMFM showed higher values because of the formation of an intermetallic bond between the metal foils and the paste. Aluminium has a yield strength of $75 \mathrm{MPa}$ and the paste has a yield strength of $45 \mathrm{MPa}$. Theoretically, these two strengths tend to add up with each layer [34]. The same increase is not obtained through experiments but Fig. 10 shows some addition in strength nonetheless. This experiment also validates the effect of increased strength with higher number of layers. $0.2 \mathrm{~mm}$ thick foils were only 9 to produce the $2.7 \mathrm{~mm}$ thick specimen, giving an increase of $6 \% ; 0.1 \mathrm{~mm}$ thick foils were 14, giving an increase of $8.25 \%$; and $0.05 \mathrm{~mm}$ thick foils were 18, thus giving $9.8 \%$ higher values. This clearly indicates that increase in number of layers increases the strength of the part produced for the same cross-sectional area.

Aluminium is a ductile metal; therefore, it shows pronounced elastic and plastic region before fracture. The composite specimens, on the other hand, show high strength but a relatively small plastic region due to the presence of bonds. The intermetallic bonds between the metal foils and the paste prevent the aluminium layers from following their ductile nature. The presence of bonds is also responsible for a much less percentage elongation of the specimens as compared to the parent aluminium as is evident from Table 6.
Table 6 Tensile test values

\begin{tabular}{lrl}
\hline Specimens & Total elongation $(\%)$ & $\begin{array}{l}\text { Ultimate tensile } \\
\text { strength (MPa) }\end{array}$ \\
\hline Al 1050 & 21.5 & 132.8 \\
$0.05 \mathrm{~mm}$ & 2.6 & 145.8 \\
$0.1 \mathrm{~mm}$ & 2.8 & 143.8 \\
$0.2 \mathrm{~mm}$ & 3.1 & 140.8 \\
\hline
\end{tabular}

\section{Comparison with plate press-soldering process}

CMFM is a relatively new process and has shown great promise in the testing stage. It has huge potential and can one day be commercialised as a cost-effective metal AM method capable of producing high-quality metal and composite parts. This process has a remarkable similarity with another process which is also in the developmental stages known as plate press-soldering (PPL). This process makes use of two massive steel plates as heat source to provide heat to metal sheets that have been coated with solder material for joining via contact heating. The process recommends the utilization of thicker plates to save time but thicker plates are more expensive than thin metal sheets. CMFM, on the other hand, can work with metal sheets of varied thicknesses without any issue as shown in the results presented in this research. PPL also required a pre-process for roughening the metal plates by sand blasting to ensure sufficient adhesion [35], whereas CMFM can work with metal foils without any surface treatment, thereby saving time and resources. The heating of the precoated metal sheets is more or less the same in both the processes. PPL claims to produce parts with lower residual stress and reduced warping but the data presented are not substantial enough, whereas we have shown in our previous work that the thermal stress and strain generated during the brazing process of CMFM is not high enough to impact the structural integrity of the final products [36]. PPL also requires reworking of the resulting part after joining according to the desired geometry, whereas CMFM does not require post-processing. The parts produced by CMFM, after joining, can be used for engineering applications. Two $100 \mathrm{~mm}$ long and $7 \mathrm{~mm}$ thick spanners, one from aluminium and the other a composite of aluminium and copper, produced by the process of CMFM are shown in Fig. 13 that clearly demonstrates the quality of parts that CMFM is capable of producing. It also shows that CMFM is not affected by the staircase effect that a number of metal foil using methods suffer from [16, 17]. It is because the layer of paste becomes solid and acts as a stiff sheet between two metal foils. Furthermore, the parts produced by CMFM show a much higher tensile strength as 


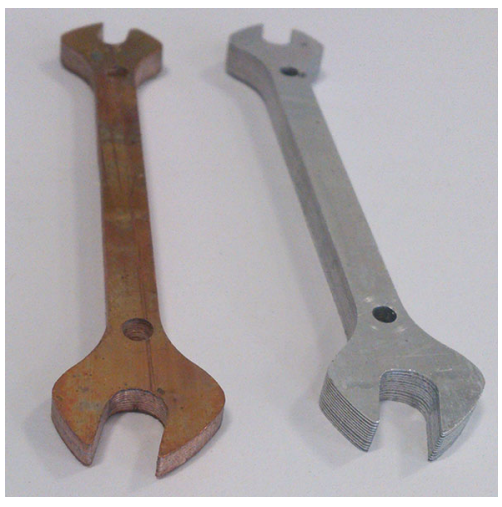

Fig. 13 Spanners produced by CMFM

compared to solid parent metals which is something that the process of PPL is struggling with. The mechanical testing of the parts produced by PPL show bending tests performed on them but they are not even comparable to the base material. A great deal of research is needed to make this process viable for the production of metal parts with good mechanical properties. It already has a pre and post process to get the desired geometry and a secondary process to enhance mechanical properties will make the build of a single part more time-consuming than it already is. The process of PPL is still in its early stages and requires more work to ensure reproducible properties of the parts and choosing a suitable solder material. It is also been aimed more towards producing large metallic tools rather than different shapes and geometries. CMFM has shown reproducible and repeatable results as shown by our previous work [37] and at this stage is a much more efficient process compared to PPL.

Scanning electron microscope (SEM) was utilized to take a closer look at the bonding interface between the paste and the metal foils (aluminium spanner from Fig. 13). Figure 14a shows that the layers of metal foil and paste are diffusing indicating the presence of a larger and stronger bonded area. A much closer look at the layer of paste in Fig. 14b showed voids and cavities indicating that even after good diffusion at the surface of the metal foil, there are still spaces within the paste layer that could lead to failure. However, those voids did not affect the mechanical properties to a large extent as during tensile testing, the parts made by CMFM proved to be stronger than solid aluminium. PPL also showed a good diffusion zone but it was not good enough to enhance the mechanical properties of parts produced by it.

\section{Potential of application}

CMFM is a very capable process and can give tough competition to the current metal AM methods. This process has the potential to follow the same pattern as three-dimensional (3D) printers have gone through in recent years. 3D printers can produce bespoke plastic parts with ease and CMFM can do the same but with metal parts. There has always been an emphasis on the production of metal parts as they provide an environment for testing and show how a part might behave under different conditions. CMFM can produce metal parts quickly, cheaply and is much simpler compared to the rival technologies.

CMFM can work with tough metals like aluminium that are not easy to join as shown through this research work. Foils of different thickness are joined using CMFM which shows the flexibility of the process. It also has the capability to produce composites in the same way as single material parts without the use of additional machinery. This feature makes the process more versatile and appealing to the metal prototyping sector. CMFM is capable of producing overhanging and complex shaped geometries with ease without compromising their mechanical integrity.

The additive manufacturing identified with the generation of metal parts using the new process can work with an extensive variety of metals under typical conditions
Fig. 14 SEM Analysis: a part at $\times 50$; $\mathbf{b}$ part at $\times 200$
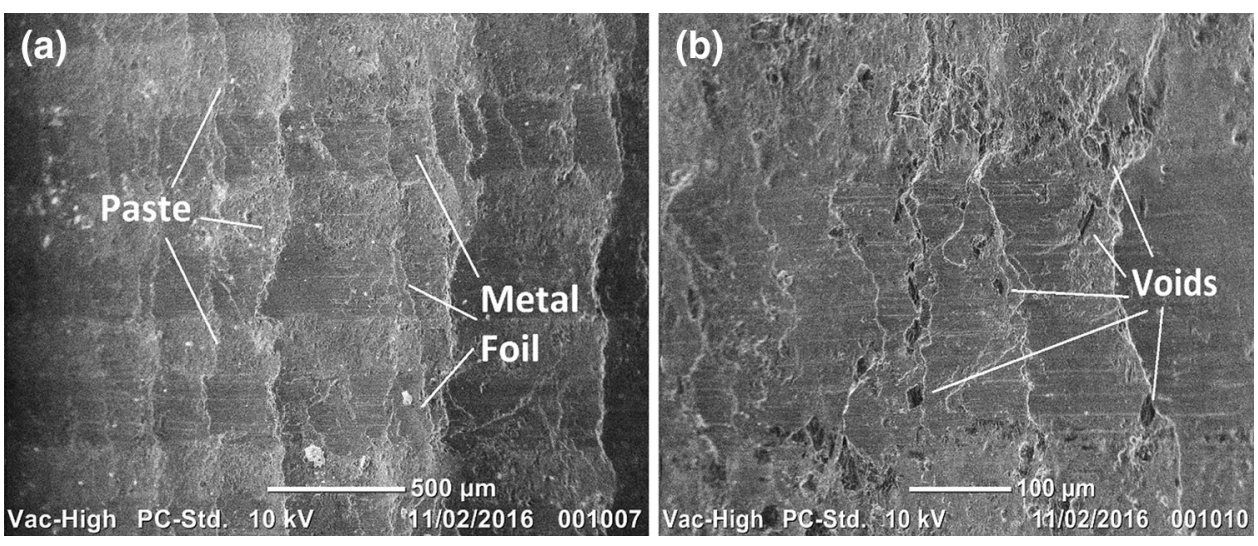
regardless of their joining capacities. The feedback that parts delivered by added substance fabrication techniques are not sufficiently solid for genuine applications can without much of a stretch is hushed with the obtained trial results. Applications can extend from little bespoke parts to large-scale functional products that can be utilized with no post handling (Fig. 13). They include but are not limited to mechanical workshop tools, motor industry (engines and their parts), large moulds, etc. This process is an addition to the list of metal AM methods and has distinct advantages including higher lap shear strength, peel strength, corrosion resistance [37], tensile strength, etc. and is well-suited for single builds.

In terms of production time, CMFM can produce parts at a much faster rate. Figure 13 shows two dog-bone specimens made by CMFM and DMLS machine (EOS M290). A visual inspection shows that the part produced by the former process (Fig. 15a) has a better surface finish and as it has already been established, possesses a higher lap shear and tensile strength. The part made by the latter process has a grainy finish (Fig. 15b) and at some areas shows impressions of the build material structure (Fig. 15c). The dog-bone specimen with a thickness of $2.7 \mathrm{~mm}$ using foils of $0.1 \mathrm{~mm}$ thickness can be made in approximately $30 \mathrm{~min}$. The same part in DMLS takes a longer time. Pre-processing of the part requires $45 \mathrm{~min}$ for the gas to fill the build chamber and 20 min for setting up and levelling of the build platform. The actual part build takes 40 min including a $4 \mathrm{~mm}$ thick support structure; otherwise the actual part would not adhere to the surface. Post-processing includes $15 \mathrm{~min}$ for powder removal after the build, 10 min for removing the part from the build platform and the support structure from the part. It clearly shows the inefficiency of a well-established metal AM method when it comes to performing single builds.
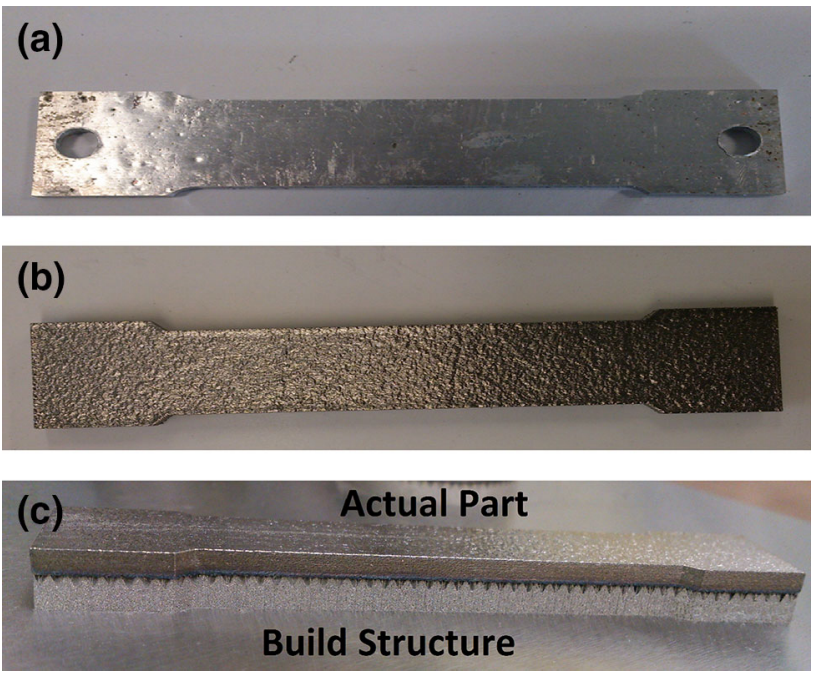

Fig. 15 Parts made by different processes: a final part by CMFM; b final part by DMLS; c Part by DMLS with support structure
The parts made by DMLS are not without inaccuracies. The accuracy depends on a number of factors including powder material, grain size, layer thickness, etc. and is an issue in all three axes. The achievable part accuracy depends on which powder material is used, varying from about $\pm 50 \mu \mathrm{m}$ for Direct-Metal 20 to about $\pm 100 \mu \mathrm{m}$ for Direct-Steel 50. The resolution in the vertical direction (perpendicular to the layers) is determined by the layer thickness. For Direct-Metal 20, Direct-Steel 20 and Direct-Steel H20 it is typically $0.02 \mathrm{~mm}$, and for DirectMetal 50 and Direct-Steel 50 it is $0.05 \mathrm{~mm}$. For DirectMetal 50 (grain size approx. $50 \mathrm{~mm}$ ) accuracies of $\pm(0.05 \%+50 \mathrm{~mm})$ are obtainable. Due to the slightly higher shrinkage during exposure and the smaller powder particle size the obtainable accuracy for Direct-Metal 20, Direct-Steel 20, Direct-Steel H20 and Direct-Steel 50 is $\pm(0.07+50 \mu \mathrm{m})[38]$. In the case of CMFM, there is not a considerable amount of inaccuracy/deformation in the $X$ and $Y$ axes [36]. The accuracy of the $Z$-axis depends on the uniformity/non-uniformity of the metal foil used and varies according to that factor. The accuracy in the vertical direction ( $Z$ axis) depends on the layer thickness and is found to be \pm 100 micron.

\section{Conclusions}

The results presented in this paper show the effectiveness of CMFM. The lap-shear testing showed two modes of failure but the failure mode was always substrate failure whereas the bonded area remained unaffected and intact. The peel test also exhibited two modes of failure with the presence of shorter and longer teeth signifying the presence of an effective and un-effective bond, respectively. The strength of the dog-bone specimens produced by CMFM is higher than the specimen produced by conventional machining method. It was argued and validated that the strength increases with increase in the number of layers for a particular cross-sectional area. The specimen produced by $0.05 \mathrm{~mm}$ thick layers showed $9.8 \%, 0.1 \mathrm{~mm}$ thick layers showed $8.25 \%$ and the specimen produced by $0.2 \mathrm{~mm}$ thick layers showed $6 \%$ higher fracture values than the parent aluminium. This is an added feature that the process can offer for the production of metal parts using foils of different thickness.

Acknowledgments The authors would like to thank Anglia Ruskin University for providing the equipment and testing facilities for carrying out the research.

\section{References}

1. Dickens PM (1995) Research developments in rapid prototyping. Proc Inst Mech Eng Part B J Eng Manuf 209(4):261-266 
2. Himmer T, Nakagawa T, Noguchi H (1997). Stereolithography of ceramics. In: international solid freeform fabrication symposium, Austin, pp 363-369

3. Kai CC (1994) Three-dimensional rapid prototyping technologies and key development areas. Comput Control Eng J 5(4):200-206

4. Pham DT, Gault RS (1998) A comparison of rapid prototyping technologies. Int J Mach Tools Manuf 38(10):1257-1287

5. Zhang Y, He X, Du S, Zhang J (2001) Al2O3 ceramics preparation by LOM (laminated object manufacturing). Int $\mathrm{J}$ Adv Manuf Technol 17(7):531-534

6. Calignano F, Manfredi D, Ambrosio EP, Iuliano L, Fino P (2013) Influence of process parameters on surface roughness of aluminum parts produced by DMLS. Int J Adv Manuf Technol 67(9-12):2743-2751

7. Cormier D, Harrysson O, West H (2004) Characterization of $\mathrm{H} 13$ steel produced via electron beam melting. Rapid Prototyp J 10(1):35-41

8. Mitchell A (1999) The electron beam melting and refining of titanium alloys. Mater Sci Eng A 263(2):217-223

9. Simchi A (2006) Direct laser sintering of metal powders: mechanism, kinetics and microstructural features. Mater Sci Eng A 428(1):148-158

10. Simchi A, Petzoldt F, Pohl H (2003) On the development of direct metal laser sintering for rapid tooling. J Mater Process Technol 141(3):319-328

11. Sonmez FO, Hahn HT (1998) Thermomechanical analysis of the laminated object manufacturing (LOM) process. Rapid Prototyp J 4(1):26-36

12. Ponader S, Vairaktaris E, Heinl P, Wilmowsky CV, Rottmair A, Körner C, Singer RF, Holst S, Schlegel KA, Neukam FW, Nkenke E (2008) Effects of topographical surface modifications of electron beam melted Ti-6Al-4 V titanium on human fetal osteoblasts. J Biomed Mater Res Part A 84(4):1111-1119

13. Murr LE, Gaytan SM, Ceylan A, Martinez E, Martinez JL, Hernandez DH, Machado BI, Ramirez DA, Medina F, Collins S, Wicker RB (2010) Characterization of titanium aluminide alloy components fabricated by additive manufacturing using electron beam melting. Acta Mater 58(5):1887-1894

14. Khaing MW, Fuh JYH, Lu L (2001) Direct metal laser sintering for rapid tooling: processing and characterisation of EOS parts. J Mater Process Technol 113(1):269-272

15. Mueller B, Kochan D (1999) Laminated object manufacturing for rapid tooling and patternmaking in foundry industry. Comput Ind 39(1):47-53

16. Prechtl M, Otto A, Geiger M (2005) Rapid tooling by laminated object manufacturing of metal foil. Trans Tech 6-8:302-312

17. Prechtl M, Pursche L, Otto A (2004) System technology and data preparation for automated laser assisted stacking of metal foil. In: Proceedings of the 4th international conference on laser assisted net shape engineering-LANE, Germany, pp. 601-610

18. Armstrong KB (1997) Long-term durability in water of aluminium alloy adhesive joints bonded with epoxy adhesives. Int $\mathbf{J}$ Adhes Adhes 17(2):89-105

19. Kinloch AJ (2003) Toughening epoxy adhesives to meet today's challenges. MRS Bull 28(06):445-448

20. Kong CY, Soar RC (2005) Fabrication of metal-matrix composites and adaptive composites using ultrasonic consolidation process. Mater Sci Eng A 412(1):12-18
21. Kong CY, Soar RC, Dickens PM (2002) An investigation of the control parameters for aluminum 3003 under ultrasonic consolidation. In: proceedings of the 13th solid freeform fabrication symposium, pp. 199-210

22. Kong CY, Soar RC, Dickens PM (2003) Characterisation of aluminium alloy 6061 for the ultrasonic consolidation process. Mater Sci Eng A 363(1):99-106

23. Facchini L, Magalini E, Robotti P, Molinari A, Höges S, Wissenbach K (2010) Ductility of a Ti-6Al-4 V alloy produced by selective laser melting of prealloyed powders. Rapid Prototyp J 16(6):450-459

24. Gu D, Shen Y (2006) WC-Co particulate reinforcing Cu matrix composites produced by direct laser sintering. Mater Lett 60(29):3664-3668

25. Kumar S, Kruth JP (2010) Composites by rapid prototyping technology. Mater Des 31(2):850-856

26. Butt J, Mebrahtu H, Shirvani H (2015) Rapid prototyping by heat diffusion of metal foil and related mechanical testing. Int $\mathbf{J}$ Adv Manuf Tech. doi:10.1007/s00170-015-7882-8

27. Butt J, Mebrahtu H, Shirvani H (2014) A novel rapid prototyping process for the production of metal parts, "proceedings of the second international conference on advances in civil, structural and mechanical engineering, Birmingham, pp 26-29. doi: 10.15224/978-1-63248-054-5-45

28. ASM Metals Handbook (1985) Heat Treating, vol 4, 9th edn. American Society for Metals, Metals Park, pp 763-774

29. BS EN 1465: 2009 Adhesives-determination of tensile lap-shear strength of bonded assemblies

30. BS EN ISO 11339:2010 Adhesives-T-peel test for flexible-toflexible bonded assemblies

31. BS EN ISO 6892-1:2009 Metallic materials-tensile testing, part 1: method of test at ambient temperature

32. BS EN ISO 10365:1995 Adhesives-designation of main failure patterns

33. Da Silva LF, Carbas RJC, Critchlow GW, Figueiredo MAV, Brown K (2009) Effect of material, geometry, surface treatment and environment on the shear strength of single lap joints. Int $\mathbf{J}$ Adhes Adhes 29(6):621-632

34. Hassan Shirvani (2000) Honeycomb structure, method of forming a honeycomb structure and method of joining aluminium or aluminium alloy bodies. Anglia Polytechnic University, GB Patent: WO0033997 (A1)

35. Strasser C, Prihodovsky A, Ploshikhin V (2015). Plate press-soldering for the manufacture of large metallic tools. https://www. rtejournal.de/ausgabe12/4242/view?set_language=en. Accessed 29 Feb 2016

36. Butt J, Mebrahtu H, Shirvani H (2015) Thermo-mechanical analysis of dissimilar al/cu foil single lap joints made by composite metal foil manufacturing. World Acad Sci Eng Technol Int J Mech Aerospa Ind Mech Manuf Eng 10(1):41-46

37. Butt J, Mebrahtu H, Shirvani H (2015) Peel and tensile test investigation of aluminium 1050 foil parts made with a new additive manufacturing process. Int J Rapid Manuf 5(1):95-115

38. Syvanen T (1996) Direct sintering of metals material and process development M.Sc. Thesis, Tampere University of Technology 